\title{
Variability of shear yield stress - measurement and implications for mineral processing
}

\author{
Adrian Knight Rheological Consulting Services Pty Ltd, Australia \\ Fiona Sofrà Rheological Consulting Services Pty Ltd, Australia \\ Anthony Stickland University of Melbourne, Australia \\ Peter Scales University of Melbourne, Australia \\ Daniel Lester RMIT University, Australia
}

Richard Buscall MSACT Research and Consulting, United Kingdom

\section{Abstract}

At high concentrations, mineral tailings exhibit solid-like behavior up to a critical shear stress, the shear yield stress $\left(\tau_{y}\right)$, which must be exceeded before flow may occur. The magnitude of $\tau_{y}$ has a significant influence upon a wide range of important mineral processing operating parameters, including pipeline pressure gradient, thickener operation and tailings beach slope, for example.

Although the concept of a critical shear stress is a simple and convenient engineering metric, in practice the transition from solid to fluid-like behavior is much more complicated, resulting in a range of apparent yield stress values that vary with the applied shear conditions. For example, in constant rate or flow start-up rheological testing, the peak stress (one measure of $\tau_{y}$ ) can more than double depending on the applied strain rate. In constant stress tests, there is a range of stress over which the slurry exhibits solid behavior over short timescales, but may yield and flow on much longer timescales. Other methods for yield stress determination, such as extrapolation from steady-state stress versus rate data, the onset of non-linearity in oscillatory flows or slump testing can generate an even broader range of yield stress values.

Whilst it is neither practical nor desirable to incorporate such complex yielding behaviour into basic models of engineering operations, it is of paramount importance to use an appropriate measure of shear yield stress for a given application. The time and rate dependencies of the selected measurement method must match the time and rate conditions of the intended application. Failure to do so can introduce significant errors with attendant design, operation and cost implications. The present work takes recent insights into the shear rheology of minerals tailings and discusses appropriate measurement techniques for a range of processing applications, including beach slope and pipeline pressure drop prediction, as well the implications of using inappropriate measurement techniques. Rheological measurements of a model system are used to demonstrate the variability of the apparent yield stress with measurement technique. Comparisons with model values of pipeline pressure drop and beach slope are used to demonstrate the scale-up implications of using inappropriate rheological data. 


\section{Introduction}

The shear yield stress of a particulate suspension is a material property which has long been used throughout minerals processing and tailings management for the design and operation of slurry mixing vessels, pumping and pipeline transport, thickening, filtration and dry stacking (Sofra and Boger, 2012; Nguyen and Boger, 1998). The shear yield stress is described as the minimum stress which must be applied for a material to irreversibly deform and flow, and has become a commonly used design parameter in that it describes a material consistency rather than a solids concentration, making it particularly useful for geotechnical design of tailings storage facilities. This is important for many processes where variations in mineralogy and/or processing conditions may result in significant changes in rheological behaviour despite the solids concentration remaining constant.

As rheological concepts and techniques have proliferated throughout the mineral industry, so too have measurement techniques for mineral suspensions evolved. Whilst the simplest means of measuring the shear yield stress remains the cone or cylinder slump test (Pashias et al., 1996; Clayton et al., 2003), such methods are currently viewed as outdated and inaccurate for more detailed design, particularly with affordable and sensitive alternatives such as the vane technique (Nguyen and Boger, 1983; Nguyen and Boger, 1985) becoming increasingly common and more affordable (Sofra and Boger, 2011). For some applications, such as basic on site quality control testing of, for instance, a cemented paste fill material, slump tests may be an adequate rheological tool. However, for applications which demand more accurate data, particularly for slurries with lower shear yield stresses, the vane technique is superior. The technique used to measure or approximate yielding behaviour must be selected with the end use of the data in mind.

Recent research into the yielding behaviour of strongly flocculated colloidal suspensions, which act as model systems analogous to many thickened and paste tailings systems, has shed further light on the intricate nature and dynamics of shear yielding and incipient flow. Of particular interest to tailings management engineers are new insights into the variability of shear yield stress as a function of measurement technique, further emphasizing the need to reconcile measurement techniques with the intended application of the data.

In this study, predictive models will be used to demonstrate the implications of using inappropriate measurement techniques for a given application, and guidelines provided for selection of appropriate techniques.

\section{Background and theory}

Recent studies aimed at probing shear yield behaviour have been undertaken on a strongly cohesive particulate suspension of calcium carbonate dispersed in a weakly ionic solution, which was coagulated at the isoelectric $\mathrm{pH}$ of approximately 8.2 (Buscall et al., 2015a; Buscall et al., 2015b). The calcium carbonate had a mean particle size of $5 \mu \mathrm{m}$, and was prepared at $40 \% \mathrm{v} / \mathrm{v}(64 \% \mathrm{w} / \mathrm{w})$.

To investigate yielding behaviour in this system, several measurement methods were employed. For each method, the measurement geometry was a vane in a cup, with the ratio of the cup to vane diameter greater than 3 to minimise wall effects (Stickland et al., 2015). Samples were tapped prior to measurement to remove air bubbles, and an equilibration time of 5 min observed prior to the application of stress or strain. Constant stress measurements were made using a TA Instruments AR G2 stress controlled rheometer, and constant strain (or rate) measurements were made using a Rheometric Scientific ARES controlled strain rheometer.

\subsection{Creep test method}

A constant stress was applied by the vane for up to $1000 \mathrm{~s}$, and the displacement of the vane recorded. Only 
one stress was applied during each measurement, with applied stresses ranging from 25 to $160 \mathrm{~Pa}$. Between each measurement, the sample was removed and stirred to remove any shear history effects from the previous measurement.

Selected data sets from creep test measurements are shown in Figure 1. At all applied stresses, viscoelastic deformation is initially observed across small time frames $(0.10 \mathrm{~s})$, after which the material either resists further deformation, or yields and flows with increasing time of applied stress.

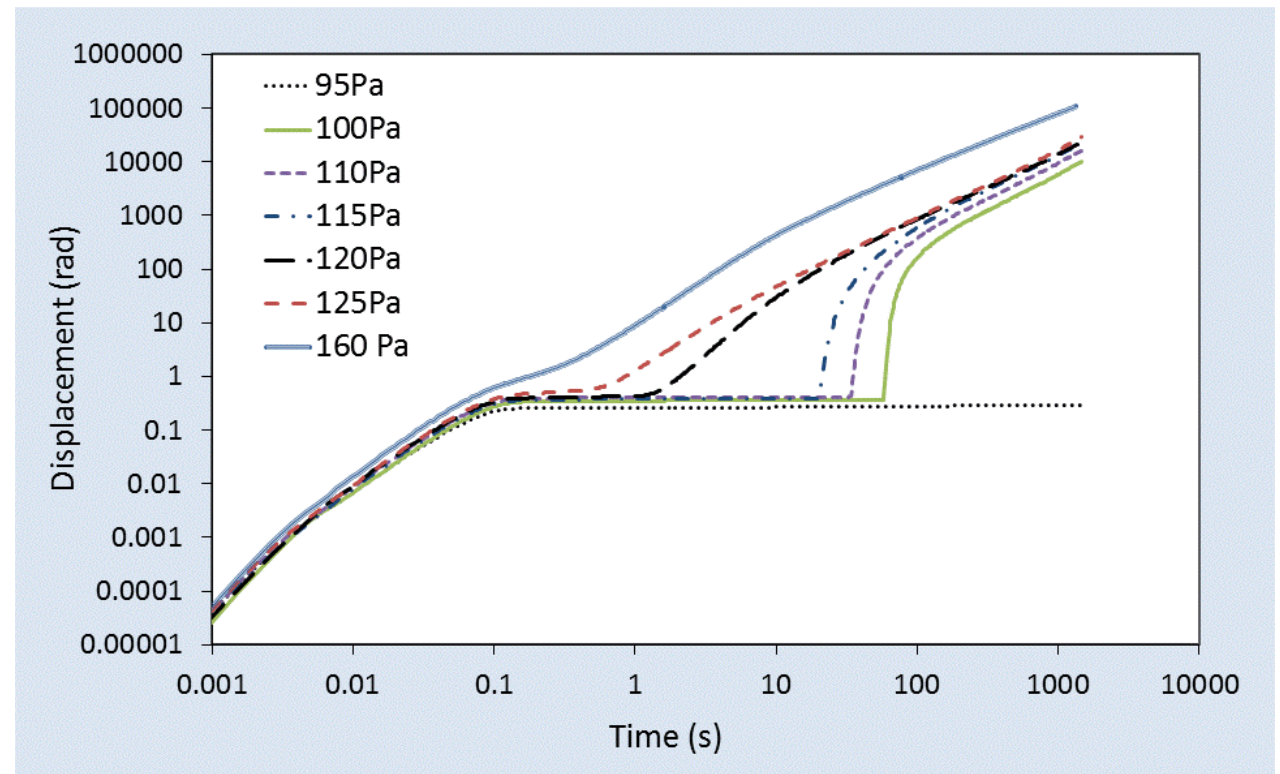

Figure 1 Displacement versus time data from creep tests on $40 \mathrm{vol} \% \mathrm{CaCO}_{3}$ system

Analysis of Figure 1 shows the complexity of the yielding behaviour of this system. A displacement above 1 was taken as the yielding criteria. A stress of $95 \mathrm{~Pa}$ applied for up to $1000 \mathrm{~s}$ does not cause the sample to flow, however an applied stress of 100 Pa caused flow after approximately $100 \mathrm{~s}$, suggesting time dependent yielding behaviour. Further increases in applied stress initiated yielding and flow at shorter time frames, with an applied stress of $125 \mathrm{~Pa}$ causing the sample to yield after $0.10 \mathrm{~s}$, and an applied stress of $160 \mathrm{~Pa}$ causing almost instantaneous yielding and flow. Hence, using this method, the shear yield stress of the sample lies in the range of $100 \sim 160 \mathrm{~Pa}$.

\subsection{Stress staircase method}

A range of stresses were applied by the vane, increasing linearly $10 \mathrm{~Pa}$ increments to $200 \mathrm{~Pa}$. Each applied stress was held for 20,40 or $60 \mathrm{~s}$, although this hold time did not affect results and as such only the 60 s hold time data is presented herein. The rotational rate of the vane was recorded, with yielding being identified by a sudden "jump" in rotational rate as seen in Figure 2. When the highest applied stress was reached, the applied stresses were decreased linearly to obtain the descending arm of the staircase.

Analysis of Figure 2 shows that, using this method, the shear yield stress of the material as measured during the ascending arm of the staircase is in the range of $70 \sim 80 \mathrm{~Pa}$, and $60 \mathrm{~Pa}$ using the descending arm of the staircase. The hysteresis seen between the up and down arms of the staircase is thought to be largely attributable to thixotropic effects (Buscall et al., 2015b). 


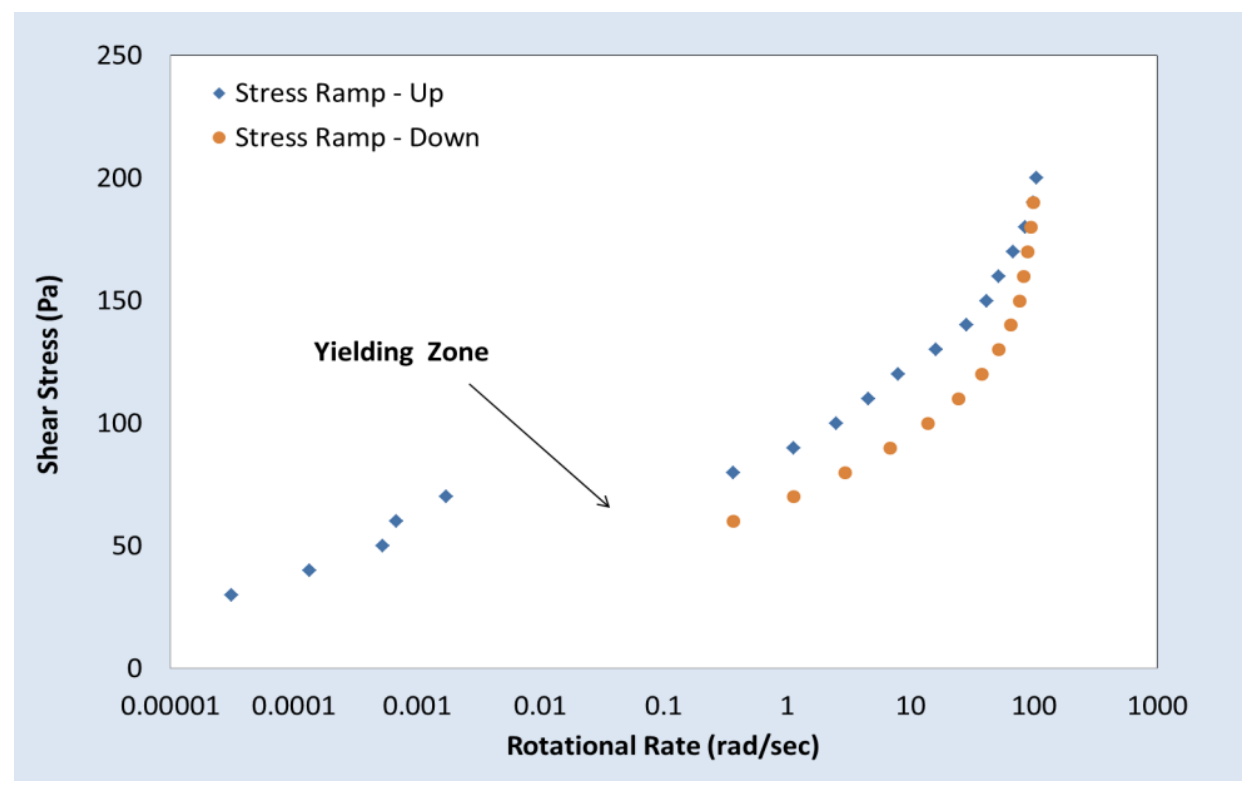

Figure 2 Shear stress versus rotational rate data from stress staircase test on 40 vol\% $\mathrm{CaCO}_{3}$ system

\subsection{Peak stress method}

The vane was rotated at constant rotational rates in the range of $10 \sim 5$ to $0.50 \mathrm{rad} / \mathrm{s}$, at each rotational rate, the peak stress as a function of time was recorded and designated as the shear yield stress of the material. The results of these measurements showed a strong dependence of the shear yield stress on rotational rate, as shown in Figure 3, where the shear yield stress varies from approximately $120 \mathrm{~Pa}$ at a rotational rate of $0.01 \mathrm{rad} / \mathrm{s}$ to approximately $250 \mathrm{~Pa}$ at the lowest rotational rates investigated.

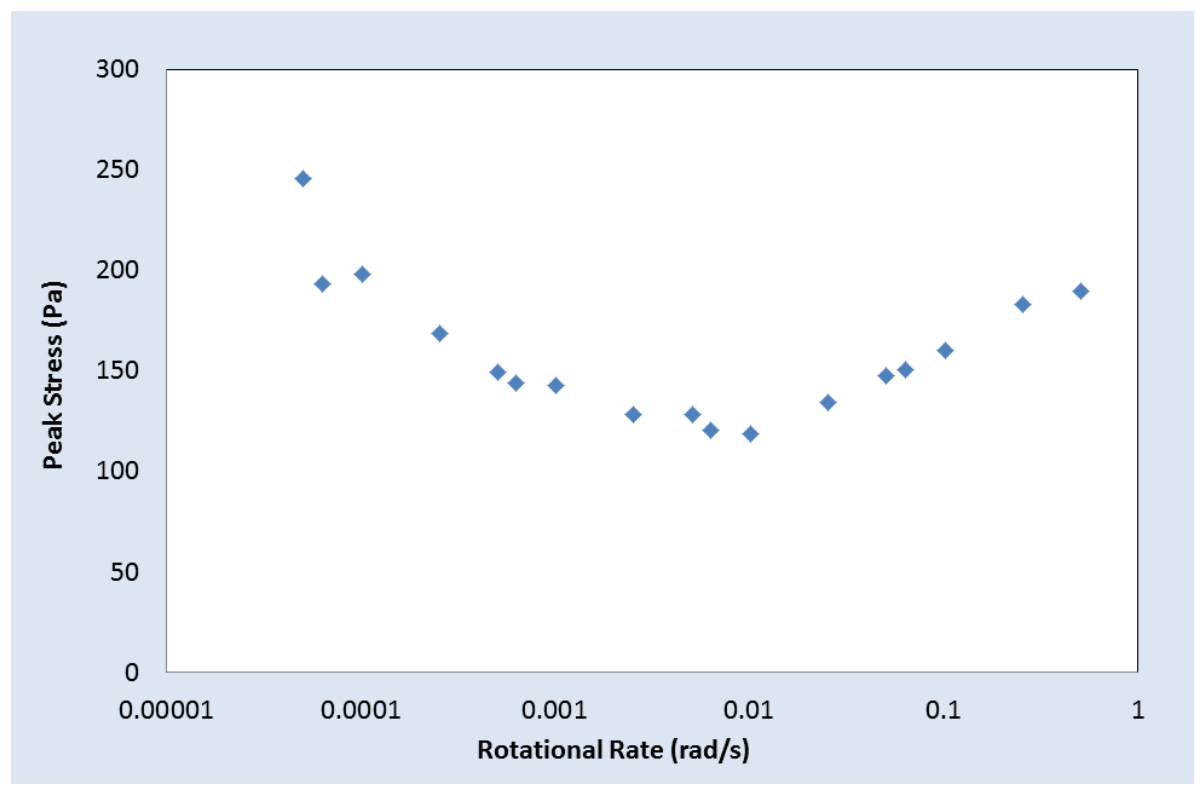

Figure 3 Peak stress versus rotational rate data from controlled rate tests on $\mathbf{4 0}$ vol\% $\mathrm{CaCO}_{3}$ system

The yield stress variations from each measurement method described above are summarised in Table 1. For further discussion, a percentage variation is included which is scaled on the lowest observed yield stress of $60 \mathrm{~Pa}$. Variations have been rounded to $\pm 5 \%$. 
Table 1 Approximate variation in apparent yield stress by method

\begin{tabular}{ccc}
\hline Method & Yield stress variation $\mathbf{( P a )}$ & Variation (\%) \\
\hline Creep test & $100 \sim 125$ & $65 \sim 110$ \\
Stress staircase & $60 \sim 80$ & $0 \sim 35$ \\
Peak stress & $120 \sim 250$ & $100 \sim 315$
\end{tabular}

A detailed explanation of the underlying causes of these phenomena is given in the source material (Buscall et al., 2015a, Buscall et al., 2015b). The minimum shear yield stress occurs at Péclet number of order unity (Buscall et al., 2015a), where the Péclet number is the ratio of viscous forces to the solid-liquid network forces. This indicates that the decrease in shear yield stress with increasing rotational rate observed at low rates $(10 \sim 5$ to $10 \sim 1 \mathrm{rad} / \mathrm{s}$ ) is due to rate dependent erosion of the particulate network, whilst the increase in shear yield stress with increasing rate at higher rates $\left(10^{-1}\right.$ to approximately $\left.0.50 \mathrm{rad} / \mathrm{s}\right)$ is due to viscous contributions. The low rotational rates allow probing of the pre-yielding viscoelastic solid behavior without inertial effects. Analysis of this region has shown that coagulated/cohesive suspensions are capable of yielding as a function of both stress and strain, which implies that the measurement method selected must be reconciled with the intended application.

Of particular interest to tailings management is that this behaviour will also be evident in polymer flocculated systems, and hence applicable to paste and thickened tailings. Investigations into industrial mineral tailings slurries have shown similar behaviour. Thickened tailings are subject to raking in thickeners, subsequent pumping, and further dewatering or deposition in a tailings storage facility. The variable yielding behaviour shown above is most likely to be important in low shear rate and long time scale regimes, such as equipment start up, thickener raking, and slow, free flows on tailings beaches.

\section{$3 \quad$ Practical implications}

\subsection{Pump and pipeline start up and operational considerations}

Variations in the measured shear yield stress have significant implications for pumping and pipeline design, especially for pump start up and optimization of pipeline parameters to minimize pressure drop during pipeline transport. From the Metzner-Reed relationship (Equation 1), the required pressured drop for flow startup of a yield stress material scales linearly with yield stress as:

$$
\tau_{o}=\frac{\Delta P D}{4 L}
$$

Where:

$\tau_{o} \quad=$ Wall shear stress, $\mathrm{Pa}$;

$\Delta P=$ Pipeline pressure drop, $\mathrm{s}^{-1} ;$

$L \quad=$ Pipe length, $\mathrm{m}$;

$D \quad=$ Pipe diameter, $\mathrm{m}$;

Based on the yield stress variation data presented in Table 1, it follows that the apparent shear yield stress can vary by up to a factor of 4 depending on the measurement method employed. For pipeline startup, the wall shear stress must exceed the yield stress of the material. As such, it is clear that critical design errors would originate from an underestimation of the shear yield stress of the material such that pumping and pipeline transport equipment is undersized. Furthermore, the variations in yielding behaviour with rotational rate as shown in Figure 3 show that yield stress can vary by a factor of 2 as a function of rotational rate, which 
suggests that efficiency can be maximized during startup by varying pump speed. Excessively slow or fast start up speeds could result in materials exhibiting much higher apparent shear yield stresses than they would at the optimal start up speed, resulting in no flow or high energy demand.

\subsection{Thickener rake torque requirements}

The overwhelming majority of clarifiers, high rate and paste thickeners incorporate rakes of varying designs which rotate around the base of the thickener and shear the bed. Whilst the primary purpose of raking is to move thickened material towards the underflow inlet, recent work has shown that the shear imparted by the rakes improves permeability and overall dewaterability, allowing for higher underflow solids and throughputs (Van Deventer et al., 2011). As such, rake design and operation are imperative to optimal thickener performance.

In this context, the variability of shear yield stress of a thickened tailings sample as a function of rotational (shear) rate, as shown in Figure 3, is of significance to thickener rake torque requirements, particularly during start up. Considering a rake as a rate controlled device, Figure 3 suggests that there is an optimum start up rate that corresponds with the minimum yield (or peak) stress in the curve. Choosing start up speeds slower or faster than this minimum will result in higher torque requirements and energy demand, with a possibility of exceeding rake motor capacity and a failure to initiate raking. Furthermore, the structural integrity of the raking mechanism and the rakes themselves may be compromised should the yield stress of the bed be higher than the design value.

\subsection{Beach slope predictions}

The observed variability in shear yield stress has significant implications for tailings stacking applications, as a layer of thickened tailings is subjected to a range of different stress and strain profiles as it flows from the point of deposition down the beach. For simplicity of exposition, discussion herein will be limited to the thickness of a theoretical deposited tailings bed which is on the threshold of downward flow, with this being related to yield stress and beach slope via Equation 2 (Liu and Mei, 1989).

$$
h=\frac{\tau_{y}}{\rho g \sin \theta}
$$

Where:

$$
\begin{aligned}
h & =\text { Theoretical bed thickness, } \mathrm{m} ; \\
\tau_{y} & =\text { Shear yield stress of the tailings, } \mathrm{Pa} ; \\
\rho & =\text { Tailings density, } \mathrm{kg} / \mathrm{m}^{3} ; \\
g & =\text { Gravitational acceleration, } 9.81 \mathrm{~m} / \mathrm{s} ; \\
\theta & =\text { Beach slope angle, }{ }^{\circ} ;
\end{aligned}
$$

A typical slurry yield stress for dry stacking of thickened tailings is approximately $20 \mathrm{~Pa}$; the percentage variation in yield stress as given in Table 1 can be applied to generate a range of possible yield stress values for the slurry depending on measurement method employed. Using a slurry density of $1680 \mathrm{~kg} / \mathrm{m}^{3}$ (calculated based on the properties of the calcium carbonate used in the model system), the impact of variations in yield stress on the predicted thickness of the deposited layer may be investigated, as shown in Figure 4.

For simplicity of analysis, the maxima of the curves in Figure 4 will be considered. For a beach slope of $1.5^{\circ}$, the variability in shear yield stress gives predicted bed heights in the range of $0.10 \sim 0.50 \mathrm{~m}$, which significantly impacts design and deposition calculations. Whilst this model remains simplistic in comparison to the sophisticated work undertaken by others in relation to beach slope prediction (Simms et al., 2011; Seddon et al., 2015; McPhail, 2015), it nonetheless demonstrates the effects that a variable yield stress can have on 
tailings deposition behaviour, and highlights the importance of selecting the correct measurement technique for the intended application.

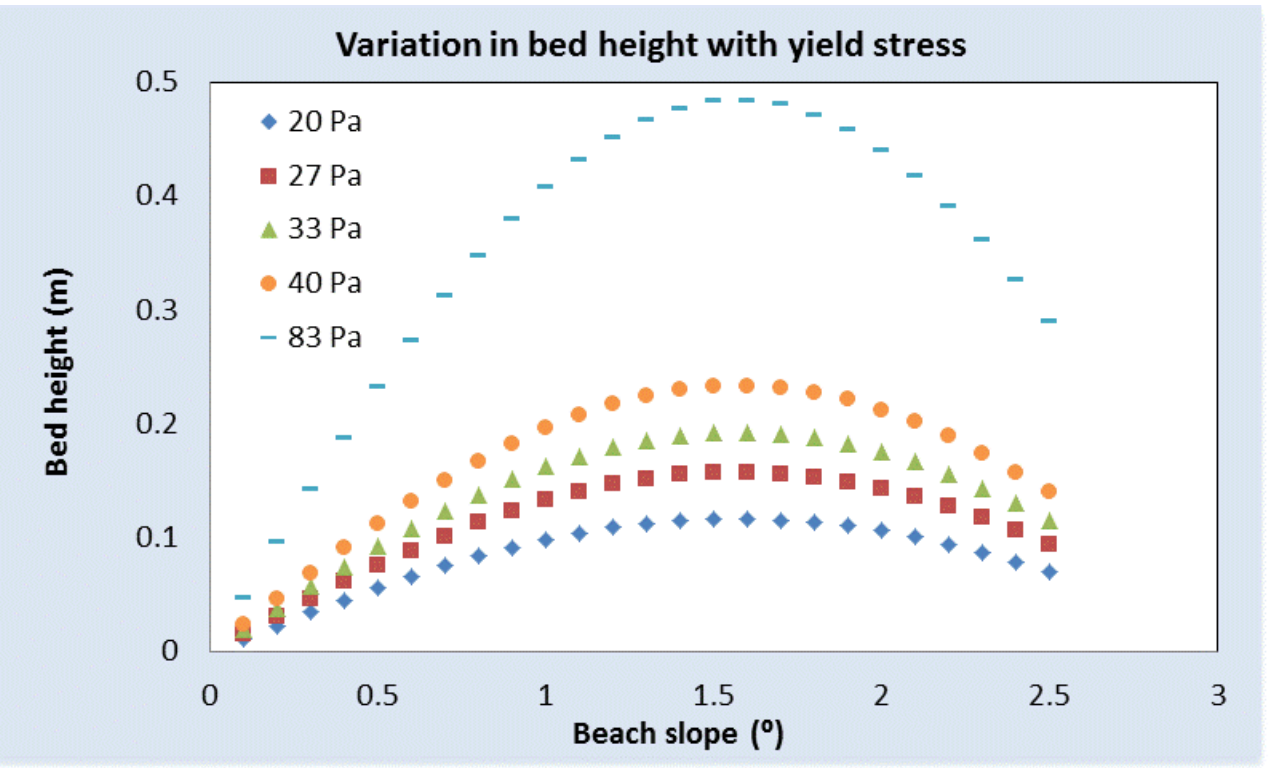

Figure 4 Relationship between yield stress and bed height for beach deposition of tailings, based on properties of 40 vol\% $\mathrm{CaCO}_{3}$ system

\section{$4 \quad$ Measurement method selection}

Based on the examples above, it is clear that inappropriate selection of yield stress measurement method for the process being considered may have significant ramifications for design and operation across a range of tailings processing, handling and disposal processes. It is therefore critical to choose the appropriate technique for the process conditions to which the data is to be applied.

The complexity of the rheological behaviour exhibited by the 40 vol\% $\mathrm{CaCO}_{3}$ system is not an artefact of instrument errors or measurement geometry; rather it is evidence of significant variations in yielding behaviour as a function of stress, strain and time. Unfortunately, such complex behaviour does not lend itself to universal rules in terms of measurement technique selection, and each application must be carefully considered to ensure that an appropriate method is used to obtain yielding data.

For many pumping and pipeline applications, the peak stress method at intermediate rotational rates (corresponding to $0.01 \mathrm{rad} / \mathrm{sec}$, or the minima of the data in Figure 3 ) is likely to suffice. At these rates, the peak stress method is analogous with the vane technique (Nguyen and Boger, 1983). Since Nguyen and Boger (1983) developed the vane technique for use on mineral slurries. It has become widely used across the minerals industry and proven sufficient for the majority of applications.

For start-up applications, the complex yielding behaviour observed is more likely to be an issue. For instance, the time dependent yielding as shown in Figure 1 suggests yielding can occur at lower yield stresses, provided the stress is applied for a long enough period of time. Similarly, for rate controlled processes, the peak stress data given in Figure 3 suggests that excessively slow start up rates may not initiate flow due to higher yield stresses at these rates, whilst start up rates greater than the minima will be subject to additional viscous stresses in order to cause the material to yield and flow.

For beach deposition and other dry stacking applications, careful consideration must be given to expected stress and shear rate profiles from deposition to rest. This is particularly significant in light of increasing industry adoption of end of pipeline treatment of slurries, whereby flocculant or other rheological modifiers 
are added to a slurry stream shortly prior to deposition to create treated slurry with a higher yield stress and improved dewaterability. The behaviour of such slurries has been shown to be highly shear sensitive (Knight and Sofra, 2016), as such their yielding behaviour is likely to be similarly complex and warrants careful consideration during measurement method selection.

\section{Conclusion}

A strongly cohesive particulate suspension of $\mathrm{CaCO}_{3}$ at $40 \mathrm{v} / \mathrm{v}(64 \% \mathrm{w} / \mathrm{w})$ was used as a model system to probe yielding behaviour under various applied stress and rate conditions. The system used is a model for many industrial coagulated and flocculated particulate slurries, with similar behaviour observed in an industrial mineral tailings sample.

The measurement methods used were creep testing, stress staircase measurements and controlled rate "peak stress" measurements. Depending on the method applied, the system was shown to yield at stresses in the range of $60 \sim 250 \mathrm{~Pa}$, which indicates complex rheological behaviour and yielding criteria which are a function of stress, strain and time.

Simple process models were used to investigate the effects that complex yielding behaviour could have on pumping, thickening and dry stacking applications. The models showed that significant differences in process predictions may arise through the use of yield stress data which does not apply to the process being considered. This highlights the important of reconciling the time and rate dependencies of the selected measurement method with the time and rate dependencies of the intended application.

\section{Acknowledgement}

The authors thank Hui-En Teo and Tiara Kusuma for undertaking the rheological measurements. Infrastructure support was provided by the Particulate Fluids Processing Centre, a Special Research Centre of the Australian Research Council.

\section{References}

Buscall, R., Kusuma, T.E., Stickland, A.D., Rubasingha, S., Scales, P.J., Teo, H., Worrall, G.L. 2015a, 'The non-monotonic shear-thinning flow of two strongly cohesive concentrated suspensions', Journal of Non-Newtonian Fluid Mechanics, vol. 222, pp. 112-120.

Buscall, R., Scales, P.J., Stickland, A.D., Teo, H., Lester, D.R. 2015b, 'Dynamic and rate-dependent yielding in model cohesive suspensions', Journal of Non-Newtonian Fluid Mechanics, vol. 221, pp. 40-54.

Clayton, S.A., Grice, T.G., Boger, D.V. 2003, 'Analysis of the slump test for on-site yield stress measurement of mineral suspensions', International Journal of Mineral Processing, vol. 70, no. 1-4, pp. 3-21.

Knight, A.P., Sofra, F. 2016, 'Laboratory studies of two end of pipe treatment technologies: observations and challenges', in S. Barrera and R.J. Jewell (eds), Proceedings of the 19th International Seminar on Paste and Thickened Tailings, Gecamin, Santiago, pp. $36-46$.

Liu, K. F. and Mei, C.C. 1989, 'Slow spreading of a sheet of bingham fluid on an inclined plane', Journal of Fluid Mechanics, vol. 207, pp. 505-529.

McPhail, G.I. 2015, 'Simulation of the meandering flow path of a beaching slurry using a random walk technique', in R.J. Jewell and A.B. Fourie (eds), Proceedings of the 18th International Seminar on Paste and Thickened Tailings, Australian Centre for Geomechanics, Perth, pp. 467-476.

Nguyen, Q.D. and Boger, D.V. 1998, 'Application of rheology to solve tailings disposal problems', International Journal of Mineral Processing, vol. 54, no. 3-4, pp. $217-233$.

Nguyen, Q.D. and Boger, D.V. 1985, 'Direct yield stress measurement with the vane method', Journal of Rheology, vol. 29, no. 3, pp. 335-437. 
Nguyen, Q.D. and Boger, D.V. 1983, 'Yield stress measurement for concentrated suspenions', Journal of Rheology, vol. 27, no. 4, pp. 321-349.

Pashias, N., Boger, D.V., Summers, J.L., Glenister, D.J. 1996, 'A fifty cent rheometer for yield stress measurement', Journal of Rheology, vol. 40, no. 6, pp. 1179-1190.

Seddon, K.D., Pirouz, B., Fitton, T.G. 2015, 'Stochiastic beach profile modelling', in R.J. Jewell and A.B. Fourie (eds), Proceedings of the 18th International Seminar on Paste and Thickened Tailings, Australian Centre for Geomechanics, Perth, pp. 455-466.

Simms, P., Williams, M.P.A., Fitton, T.G., McPhail, G. 2011, 'Beaching angles and evolution of stack geometry for thickened tailings - a review', in R.J. Jewell and A.B. Fourie (eds), Proceedings of the 14th International Seminar on Paste and Thickened Tailings, Australian Centre for Geomechanics, Perth, pp. 323-338.

Sofra, F. and Boger, D.V. 2002, 'Environmental rheology for waste minimisation in the minerals industry', the Chemical Engineering Journal, vol. 86, no. 3, pp. 319-330.

Sofra, F. and Boger, D.V. 2011, 'Rheology for thickened tailings and paste - history, state-of-the-art and future directions', in R.J. Jewell and A.B. Fourie (eds), Proceedings of the 14th International Seminar on Paste and Thickened Tailings, Australian Centre for Geomechanics, Perth, pp. 121-134.

Stickland, A.D., Kumar, A., Kusuma, T.E., Scales, P.J., Tindley, A., Biggs, S., Buscall, R. 2015, 'The effect of premature wall yield on the creep testing of strongly flocculated suspensions', Rheologica Acta, vol. 54, no. 5, pp. 337-352.

Van Deventer, B.B.G., Usher, S.P., Kumar, A., Rudman, M.,Scales, P.J. 2011, 'Aggregate densification and batch settling', Chemical Engineering Journal, vol. 171, no. 1, pp. 141-151. 